\title{
Prevalence of tobacco smoking and KAP about smoking among medical students in a private college in Central Kerala
}

\author{
Kumar Singh R. ${ }^{{ }^{*}}$ \\ DOI: https://doi.org/10.17511/ijphr.2016.i5.03 \\ 1* Rajiv Kumar Singh, Associate Professor, Department of Community Medicine, Melmaruvathur Adhiprashakthi Institute of Medical
Sciences (The Tamil Nadu Dr. M.G.R. Medical University), Melmaruvathur, Tamil Nadu, India.
}

Background: Smoking is a leading cause of preventable death, killing more than 5 million yearly. Smoking among health care personnel such as medical students is an important public health issue. This study was done to understand and in future find effective measures to reduce tobacco smoking among medical students. Objectives: To find the prevalence and to assess knowledge, attitude and practice of tobacco smoking among students of a Private Medical College in Central Kerala. Material and Methods: Cross-sectional study, using pretested, anonymous questionnaire, was conducted in a private medical college in central Kerala and proportions, test of significance like $x^{2}$ and t test were used. Results: Out of 342 students, 26 (7.6\%) were smokers; Males 25 (21.0\%, out of 119), females $1(0.44 \%$ out of 223$), 72(21.1 \%)$ had ever smoked; of which 60 were males $(50.42 \%)$ and $12(5.38 \%)$ were females; 82 (24\%) had family members who smoked; $196(57.3 \%)$ had relatives who smoked; and 184 (53.8\%) had a smoker in their friend circle. $68.4 \%$ of students do not like to socialize or engage in activities with smokers. 17 (53.2\% of smokers) want to quit smoking; 17 (51.5\% of smokers) claimed to have a relapse. Conclusions: Smokers are predominantly more between 21-26 years of age. Most of students started the habit of smoking between 16-20 years of age, therefore it is necessary to bring positive behavioral changes through adoption of comprehensive awareness programs on harmful effects of smoking among adolescent school going children.

Keywords: KAP, Medical students, Prevalence, Smoking

Corresponding Author

Rajiv Kumar Singh, Associate Professor, Department of Community Medicine, Melmaruvathur Adhiprashakthi Institute of Medical Sciences (The Tamil Nadu Dr. M.G.R. Medical University), Melmaruvathur, Tamil Nadu, India. Email: rajiv101@gmail.com
How to Cite this Article

Singh RK. Prevalence of tobacco smoking and KAP about smoking among medical students in a private college in Central Kerala. Public Health Rev Int J Public Health Res. 2016;3(5):195-199.

Available From

https://publichealth.medresearch.in/index.php/ijphr/ article/view/51
To Browse

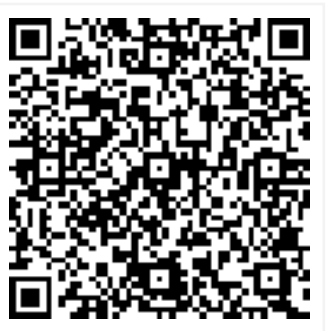

Manuscript Received 2016-09-09

Conflict of Interest No

Review Round 1
2016-09-16
Funding
Nil

Review Round 1 Nil

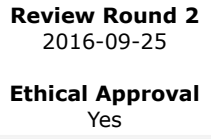

Review Round 3

Plagiarism X-checker $9 \%$
Accepted 2016-10-08

Note

(c) 2016 by Rajiv Kumar Singh and Published by Siddharth Health Research and Social Welfare Society. This is an Open Access article licensed under a Creative Commons Attribution 4.0 International License https://creativecommons.org/licenses/by/4.0/ unported [CC BY 4.0]. 


\section{Introduction}

Smoking is a problem with worldwide dimension. It is one of the most important causes of pulmonary and cardiac diseases. Government of India has passed a law not just highlighting the dangers of smoking but also banning it in various forms to protect the health of the public [1].

Health professionals, including medical students, should ideally play an important role in the fight against tobacco use but several reports suggest that a good number of medical students are themselves addicted to tobacco. We need to take steps to stop its use by them so as to prevent them from being exposed to its hazardous effects. This will also make their role in the advocacy of the smoking cessation activities more trustworthy [2].

As medical students, who are usually in their adolescence, progress through the medical school, their behavior regarding the use of tobacco equals or even exceeds the rates in the non-medical peer groups, despite their knowledge of smoking-related diseases. As such, many researchers have historically investigated tobacco-smoking rates among this demographic group [3].

As future physicians who will witness the continued burden of smoking-related diseases among their patients, medical students represent a primary target for tobacco-prevention programs. A recent study in Kerala showed that substantial proportion of physicians and medical students continue to smoke [3].

Over the past 60 years many studies have been done, in which recent studies among medical students show- Prevalence of smoking in south India was found to be $22.4 \%$ [2]; In Orissa in the year 2005 the prevalence of smoking was $8.7 \%$ [3]. The prevalence of smoking among tobacco users (28.8\%) was found to be $87.5 \%$ in a study conducted in Lucknow in the year 2008 [4]. In a study done in Allahabad prevalence of smoking was $33 \%$ out of 560 responders [5]. Prevalence of smoking was observed as $5.5 \%$ in Kannur district of Kerala in the year 2011 [6]. There was $32.55 \%$ prevalence of smoking in Maharashtra in the year 2008 [7].

This study was done to understand the magnitude of current smoking scenario and to find effective measures to reduce tobacco smoking among medical students in future.

\section{Aims and Objectives}

To study the prevalence of tobacco smoking among students of a Private Medical College in Central Kerala and to assess knowledge, attitude and practice of tobacco smoking among students.

\section{Material and Methods}

A cross-sectional study was designed in a private medical college in Central Kerala and covered all the students in the month of November 2015.

Permission for the study was taken from Institutional Research Committee and Institutional Ethics Committee. Data was collected using a pretested, anonymous, questionnaire. The students were briefed about the purpose of the study; their consent was obtained before filling the questionnaire. They were reassured about the anonymity and confidentiality of the information. The collected data was tabulated using MS Excel and analyzed using Epi Info 7. Significance was found using $x$ 2test and t-test.

\section{Results}

Demographic profile: Responses from 342 students were included in the survey. The mean age of our study subjects was 20.80 years. Among the total responders, 119 (34.8\%) were males and 223 $(65.2 \%)$ were females; $16(19.9 \%)$ were Christians, $226(66.1 \%)$ were Hindus and 48 (14.0\%) were Muslims; $170(49.7 \%)$ were from rural area and 172 (50.3\%) were from urban area; 34 (9.9\%) were day scholars and $342(90.1 \%)$ were hostellers.

Prevalence: Out of 342 students, 26 (7.6\%) were smokers; Males 25 (21.0\%) out of 119 , female 1 $(0.44 \%)$ out of 223 . Seventy two $(21.1 \%)$ had ever smoked; of which 60 were males $(50.42 \%)$ and 12 $(5.38 \%)$ were females. Out of 72 ever-smokers, the age for trying cigarettes was under 10 years for 10 $(13.88 \%), 11$ to 15 years for $12(16.66 \%), 16$ to 20 years for $31(43.05 \%)$ and for 21 years old or above for $19(26.38 \%)$. Out of $342,82(24 \%)$ had family members who smoked; $196(57.3 \%)$ had relatives who smoked; and $184(53.8 \%)$ had a smoker in their friend circle.

Knowledge: See table 1 for knowledge of students about facts associated with smoking.

Attitude: Seventeen (53.2\%) want to quit smoking and $7(2.2 \%)$ want to start smoking. For other things in attitude see table 2 . 
Table-1: Knowledge related to Smoking.

( $N=342$.

\begin{tabular}{|l|l|c|}
\hline \multicolumn{1}{|c|}{ Knowledge About } & \multicolumn{1}{|c|}{$\begin{array}{c}\text { Not Aware } \\
(\%)\end{array}$} & \multicolumn{1}{|c|}{$\begin{array}{c}\text { Aware } \\
(\%)\end{array}$} \\
\hline Carcinoma of lung, gums \& Oral Cavity & $1(0.3)$ & $341(99.7)$ \\
\hline Smoking leads to Sterility & $32(9.4)$ & $310(90.6)$ \\
\hline Harmful effect of Passive Smoking & $7(2.0)$ & $335(98.0)$ \\
\hline $\begin{array}{l}\text { Cigarette contains Harmful Substances like } \\
\text { Nicotine \& Tar }\end{array}$ & $2(0.6)$ & $340(99.4)$ \\
\hline Statutory Warning given on cigarette packets & $3(0.9)$ & $339(99.1)$ \\
\hline Smoking in Public Places is illegal & $3(0.9)$ & $339(99.1)$ \\
\hline Quitting smoking good for health & $14(4.1)$ & $328(95.9)$ \\
\hline
\end{tabular}

\begin{tabular}{|l|l|l|}
\hline $\begin{array}{l}\text { Pathological Changes will Reverse if Smoking } \\
\text { Stopped }\end{array}$ & $41(12.0)$ & $301(88.0)$ \\
\hline
\end{tabular}

Table-2: Attitude about Smoking

\begin{tabular}{|l|l|}
\hline \multicolumn{1}{|c|}{ Attitude } & $\begin{array}{c}\text { Positive Response } \\
(\%)\end{array}$ \\
\hline $\begin{array}{l}\text { Quit Smoking Programs will help in successfully } \\
\text { quitting smoking }\end{array}$ & $249(72.8)$ \\
\hline Smoking Gives Pleasurable Feeling & $31(9.1)$ \\
\hline Smoking Relieves Stress & $29(8.5)$ \\
\hline Smoking Increases Focus and Concentration & $13(3.8)$ \\
\hline Smoking gives a Feeling of Relaxation & $32(9.4)$ \\
\hline
\end{tabular}

Table-3: Association of Smokers and Nonsmokers with various factors $(\mathbf{N}=\mathbf{3 4 2})$

\begin{tabular}{|c|c|c|c|c|c|}
\hline \multicolumn{2}{|c|}{ Variables } & Smoker $(\%)$ & Nonsmoker $(\%)$ & $x^{2}$ & $P$ value \\
\hline \multirow[t]{2}{*}{ Sex } & Female & $1(0.4)$ & $222(99.6)$ & \multirow[t]{2}{*}{46.694} & \multirow[t]{2}{*}{0.000} \\
\hline & Male & $25(21.0)$ & $94(79.0)$ & & \\
\hline \multirow[t]{2}{*}{ Age } & Young (17-20 Years) & $3(2.2)$ & $134(97.8)$ & \multirow[t]{2}{*}{9.532} & \multirow[t]{2}{*}{0.002} \\
\hline & Older (21-26 Years) & $23(11.2)$ & $182(88.8)$ & & \\
\hline \multirow[t]{2}{*}{ Smoker in the family } & Yes & $12(14.6)$ & $70(85.4)$ & \multirow[t]{2}{*}{7.593} & \multirow[t]{2}{*}{0.006} \\
\hline & No & $14(5.4)$ & $246(94.6)$ & & \\
\hline \multirow[t]{2}{*}{ Relative Smoker } & Yes & $22(11.2)$ & $174(88.8)$ & \multirow[t]{2}{*}{8.575} & \multirow[t]{2}{*}{0.003} \\
\hline & No & $4(2.7)$ & $142(97.3)$ & & \\
\hline \multirow[t]{2}{*}{ Smoker in Friend Circle } & Yes & $26(14.1)$ & $158(85.9)$ & \multirow[t]{2}{*}{24.163} & \multirow[t]{2}{*}{0.00} \\
\hline & No & $0(0.0)$ & $158(100)$ & & \\
\hline \multirow[t]{2}{*}{ Smoking Program can Help Quit } & Yes & $12(4.8)$ & $237(95.2)$ & \multirow[t]{2}{*}{10.097} & \multirow[t]{2}{*}{0.001} \\
\hline & No & $14(15.1)$ & 79 (84.9) & & \\
\hline \multirow[t]{2}{*}{ Smoking Pleasant Feeling } & Yes & $14(45.2)$ & $17(54.8)$ & \multirow[t]{2}{*}{62.708} & \multirow[t]{2}{*}{0.000} \\
\hline & No & $12(3.9)$ & $299(96.1)$ & & \\
\hline \multirow[t]{2}{*}{ Smoking Relieves Stress } & Yes & $12(41.4)$ & $14(58.6)$ & \multirow[t]{2}{*}{46.345} & \multirow[t]{2}{*}{0.000} \\
\hline & No & $14(4.5)$ & $299(95.5)$ & & \\
\hline \multirow[t]{2}{*}{ Smoking Increases Focus \& Concentration } & Yes & $8(61.5)$ & $5(38.5)$ & \multirow[t]{2}{*}{48.26} & \multirow[t]{2}{*}{0.000} \\
\hline & No & $18(5.5)$ & $311(94.5)$ & & \\
\hline \multirow[t]{2}{*}{ Smoking Gives Relaxed Feeling } & Yes & $20(62.5)$ & $12(35.5)$ & \multirow[t]{2}{*}{142.966} & \multirow[t]{2}{*}{0.000} \\
\hline & No & $6(1.9)$ & $304(98.1)$ & & \\
\hline
\end{tabular}

Practice: Among the smokers, 22 (78.57\%, mild smokers) were smoking less than 10 cigarettes per day, 3 (17.85\%, moderate smokers) were smoking 10 to 20 , and 1 (3.5\%) was severe smoker, smoking more than 20 cigarettes per day. Among the smokers, 22 (73.3\%) were spending less than 100 rupees and $4(26.7 \%)$ were spending more than 100 rupees per day.

Eleven (3.2\% of the total and $34.37 \%$ of smokers) claimed to smoke in the college campus outside the hostel. Fifteen (4.4\% of total and $46.89 \%$ of smokers) have thought of quitting smoking in the last one month and the same applies for attempt to quit in the last one year.
Four ( $1.2 \%$ of the total and $12.5 \%$ of smokers) never share their cigarette, eight $(2.3 \%$ of the total and $25 \%$ of the smokers) sometimes share their cigarette with someone else, and 20 (5.8\% of the total and $62.5 \%$ of the smokers) usually share their cigarettes with their friends.

Thirteen (3.8\% of the total and $40.63 \%$ of the smokers) considered themselves to be social smokers as compared to 19 (5.6\% of the total and $59.37 \%$ of the smokers) considered themselves to be regular smokers. Out of $342(100 \%)$ of the subjects, only 108 (31.6\%) like to socialize or engage in activities with smokers. 


\section{Discussion}

Prevalence: This study showed a prevalence of $7.6 \%$ total; $21.0 \%$ for male subgroup and $0.44 \%$ for females. Study by Joge et al show a prevalence of $32.5 \%$, which was from Maharashtra state and study by Ganesh Kumar et al in 2011 shows a prevalence of $22.4 \%$ from Kerala among male medical students, this can be compared with our study [2][8]. The prevalence in girls is $0.44 \%$ and for ever-smoked the prevalence is $5.38 \%$ which reflects the change in culture that is showing up these days. We also see that $67.43 \%$ of the hostellers had tried smoking between the ages of 16-26 years. Similar findings were observed in the study of Swathy et al among medical students where prevalence of smoking among hostellers was found to be $68.27 \%$.

Knowledge: In our study, more than $95 \%$ of the responders are strongly aware of the hazardous effects of smoking. The knowledge of awareness about sterility caused by smoking and reversal of pathological changes in 10-15 years of quitting smoking was lacking in $32(9.4 \%)$ and $41(12.0 \%)$ of students, respectively, was a major finding. In a study conducted by Chatterjee among medical and non-medical students of Kolkata, $98 \%$ of smokers among medical students had knowledge on the harmful effects of smoking. In a similar study by Al Haqwi et al in Riyadh, $94 \%$ of the study sample indicated that smoking could cause serious ill effects.

Practice: Most smokers were mild or moderate smokers, smoking less than 20 cigarettes a day and were spending less than Rs. 100/- per day on smoking. Unlike us, Gupta et al found that students were spending more than Rs 200/- per month [9]. Eleven (3.2\% of the total and $34.37 \%$ of smokers) claimed to smoke on the college property excluding the hostel, even though smoking is completely banned on the college property, outside the hostel. Harini Priya et al showed that approximately $47 \%$ of current smokers had smoked on college property. [10] Unlike Ganesh Kumar et al, we did not find that students from rich families are more likely to be smokers, but like them we did find those with family history of smoking are more likely to smoke [2].

Thirteen $(3.8 \%$ of the total and $40.63 \%$ of the smokers) considered themselves to be social smokers as compared to 19 (5.6\% of the total and $59.37 \%$ of the smokers) considered themselves to be regular smokers.
There is no student who suffers serious nicotine addiction or functional impairment, as none opted for the choice of having the need to smoke every hour.

Attitude: More than half the smokers in our study (53.2\%) want to quit smoking. Aggarwal et al, showed that $68.75 \%$ current smokers would try to quit smoking in the future.[8] Likewise, Swathy et al found $63.13 \%$ and Joge et al observed $42.03 \%$ of their study subjects wanting to quit smoking.[7] [11]

In the present study, last one year after quitting smoking $51.5 \%$ of smokers who tried quitting, had relapse. This clearly shows that half the smokers are not happily adjusted to their smoking habit and have tried to quit. Similarly, Harini Priya et al found majority of the current consumers $(60 \%)$ had attempted to quit but $56.92 \%$ had again restarted the habit of tobacco consumption.[10]

\section{Conclusions \& Recommendations}

In the present study, prevalence of smoking was found to be $7.6 \%$. Besides, it was observed that smoking habit is more among males ( $21 \%$ of total males). Smokers are predominantly between 21-26 years of age. It was also seen that $53.2 \%$ of smokers wanted to quit smoking. Most of students started the habit of smoking between 16-20 years of age, therefore:

It is necessary to bring positive behavioral changes through adoption of comprehensive awareness programs on harmful effects of smoking among adolescent school going children. Those who are severely addicted to smoking can be encouraged to join de-addiction programs. Initiation of health campaigns among medical students to remind them of the hazardous effects of smoking and its addictions, with the involvement of departments of Community Medicine and Psychiatry.

\section{Acknowledgement}

I would like to thank and express our gratitude to Commodore (Dr.) MJ John and Professor (Dr.) Raju Antony for their continued support and guidance without which we would not be able to complete this study honestly. I would also acknowledge the help of House Surgeons Dr. Nizaj Nasimudeen, Dr. Prannoy Pavanan, Dr. Ramzeen M Sulaiman, Dr. Reeshma Jose, Dr. Remyasree C Remabai. 


\section{Reference}

01. Cigarettes and tobacco products (Prohibition of Advertisement and Regulation of Trade and Commerce, Production, Supply and Distribution) Act. 2003.

[Article] [Crossref]

02. Kumar SG, Subba SH, Unnikrishnan B, Jain A, Badiger $S$. Prevalence and factors associated with current smoking among medical students in Coastal South India. Kathmandu Univ Med J. 2011;9;36(4)233-7.

[Crossref]

03. Ramakrishna GS, Sarma PS, Thankappan KR. Tobacco use among medical students in Orissa. Natl Med J India. 2005 Nov-Dec;18(6)285-9. [Crossref]

04. Kumari R, Nath B. Study on the Use of Tobacco among Male Medical Students in Lucknow, India. Indian J Community Med. 2008 Apr;33(2)100-3. [Crossref]

05. Mehrotra R, Chaudhary AK, Pandya S, Mehrotra KA, Singh $M$. Tobacco Use by Indian Medical Students and the Need for Comprehensive Intervention Strategies. Asian Pac J Cancer Prev. 2010;11(2)349-52.

[Crossref]

06. Muttappallymyalil J, Divakaran B, Thomas T, Sreedharan J, Haran JC, Mohammed T. Prevalence of Tobacco Use among Adolescents in India. Asian Pac J Cancer Prev. 2012;13(11)5371-4.

[Crossref]

07. Joge US, Malkar VR, Choudhari SG, Raut MM, Ughade HM. Prevalence and the Factors Associated with Tobacco Smoking among Students of a Medical Teaching institute. Int J Med Health Sci. 2013 Jan;2;23-9.

[Crossref]

08. Aggarwal S, Sharma V, Randhawa $H$, Singh $H$. Knowledge, attitude and prevalence of use of tobacco among medical students in India- A single center cross sectional study. Annals of Trop Medi \& Pub Heal. 2012;5(4)327-9.

[Crossref]

09. Gupta AK, Mazta SR, Saurabh K, Ivan J. Prevalence of use of Tobacco among Male Medical Students in IGMC Shimla, Himachal Pradesh, India. JIMSA. Oct-Dec 2012;25(4)241. [Crossref]
10. Harini PM, Bhat SS, Sundeep HK. Prevalence, Knowledge and Attitude of Tobacco Use among Health Professionals in Mangalore City, Karnataka. J Oral Health Comm Dent. 2008;2(2)19-24.

[Crossref]

11. Khan S, Mahmood SE, Sharma AK, Khan F. Tobacco use among medical students- Are they the role models of the society?. Journal of Clinical and Diagnostic Research. 2012 May;6;605-7. [Crossref] 